\title{
“VOU LEVAR FLORES NO MAR”: REFERÊNCIAS RELIGIOSAS, CULTURAIS E PATRIMONIAIS NAS FESTAS DE IEMANJÁ DAS PRAIAS DO CASSINO E DO LARANJAL NO RIO GRANDE DO SUL ${ }^{1}$
}

"I'M TAKING FLOWERS TO THE SEA": RELIGIOUS, CULTURAL AND

HERITAGE REFERENCES IN IEMANJÁ FEASTS ON THE BEACHES

OF CASSINO AND LARANJAL IN RIO GRANDE DO SUL

Enviado em 1 de março de 2015

Aceito em 4 de junho de 2015

Mauro Dillmann Tavares ${ }^{2}$

Carmem Gessilda Burgert Schiavon ${ }^{3}$

\begin{abstract}
Resumo: Este ensaio visual tem por objetivo destacar alguns elementos simbólicos das comemorações religiosas das festas de lemanjá, ocorridas no dia 02 de fevereiro de 2015, nas praias do Cassino, em Rio Grande/RS, e do Laranjal, em Pelotas/RS, a partir de registros fotográficos realizados pelos autores. Atentos à praia enquanto lugar de diferentes sentidos, entre os quais, o de expressão simbólica de sentimentos religiosos e festividade, nossa intenção consiste em apresentar algumas reflexões sobre experiências religiosas de matriz africana destas festas e suas referências culturais e patrimoniais significadas e representadas na contemporaneidade nestas duas cidades do sul do Brasil.
\end{abstract}

Palavras-chave: Religiosidade afro-brasileira. lemanjá. Patrimônio.

Abstract: This visual essay aims to highlight some of the symbolic elements present in the religious celebrations held in honor of lemanjáon February $2^{\text {nd }}$, 2015 at two beaches located in the southern Brazilian state of Rio Grande do Sul: Cassino beach in Rio Grande and Laranjal beach in Pelotas. This essay is based on

\footnotetext{
1 O presente texto apresenta resultados parciais do Programa intitulado "Inventário(s) do(s) patrimônio(s) como instrumento para a investigação e compreensão dos nós que compõem a tessitura da rede das manifestações culturais do Município do Rio Grande", financiado pelo Programa de Extensão Universitária (ProExt) do Ministério da Educação.

\begin{abstract}
2 Bacharel em História pela Universidade Federal de Pelotas. Mestre e Doutor em História pela Universidade do Vale do Rio dos Sinos, Unisinos/RS. Professor de Graduação e de Pós-Graduação vinculado ao Mestrado Profissional em História da Universidade Federal do Rio Grande (FURG). E-mail: maurodillmann@furg.br

3 Graduada em História, Licenciatura Plena, pela Universidade Federal do Rio Grande. Mestre e Doutora em História pela Pontifícia Universidade Católica do Rio Grande do Sul (PUCRS). Professora de Graduação e de Pós-Graduação vinculada ao Programa em História e ao Mestrado Profissional em Ensino de História em Rede Nacional da Universidade Federal do Rio Grande (FURG).
\end{abstract}


the authors' own photographic records. Conceiving "the beach" as a place of diverse meanings, for example, a location of symbolic expressions of religious and festive sentiments, the essay'sintention is to reflect on the experiences of religions of African origin in these celebrations. The essay also intends to reflect on the cultural and heritage references of these religions that are represented and given meaning in the contemporary societies of these two southern Brazilian cities.

Keywords: Afro-Brazilian religions, lemanjá. Heritage.

... ela ouve as preces das mulheres marítimas, desencadeia as tempestades, escolhe os homens que há-de levar para o passeio infindável do fundo do mar. E é ali que se realiza a sua festa, mais bonita que todas as procissões da Bahia, mais bonita que todas as macumbas, que ela é dos orixás mais poderosos, ela é dos primeiros, daqueles donde os outros vieram. [...] Porque é uma beleza na noite da festa de lemanjá.

Jorge Amado, Mar Morto

O escritor baiano Jorge Amado no seu romance Mar Morto, publicado em 1936, referenciava a popularidade da devoção e da festa ao orixá lemanjá na Bahia, destacando ser "ali [no mar] que se realiza a sua festa", adjetivada como "bonita" e de evidente "beleza".

Atualmente, quase 80 anos depois da publicação desta famosa obra de Jorge Amado, a devoção à lemanjá se encontra difundida e grandemente popularizada no Brasil, especialmente no litoral e, inclusive, no sul do país. Em duas importantes cidades do sul do Rio Grande do Sul, Pelotas e Rio Grande, as festas anuais de lemanjá, no dia dois de fevereiro, são fenômenos religiosos que podem ser estudados do ponto de vista histórico, antropológico, sociológico, teológico, artístico e patrimonial.

Desse modo, este ensaio visual tem por objetivo destacar alguns elementos simbólicos das comemorações religiosas das festas de lemanjá - identificadas como referências religiosas, culturais e patrimoniais - realizadas no dia 02 de fevereiro de 2015, nas praias do Cassino, em Rio Grande/RS, e do Laranjal, em Pelotas/RS, a partir de fotografias. A praia, o mar ou a lagoa, ganham, nesta data, sentidos de lugares que expressam simbolicamente diversos sentimentos e interesses, mas que, de fato, conjugam tradição, religiosidade e festividade. Com base na observação participante, no sentido antropológico, ${ }^{4}$ apresentamos algumas fotografias realizadas pelos

4 Uma etnografia baseada na observação participante apresenta-se como metodologia antropológica, apoiada no ver, no ouvir, no "estar junto" e no escrever para compreender determinados aspectos da vida 
pesquisadores/autores durantes as festas, a fim de promover reflexões sobre as referências religiosas culturais que elas apresentam/representam e sobre o seu caráter patrimonial. $^{5}$

Como festas religiosas consolidadas, tornaram-se referências culturais importantes nas referidas cidades, pois mobilizam não apenas grupos religiosos de matriz africana, ${ }^{6}$ mas também devotos leigos, curiosos e indivíduos que, independentes do direcionamento religioso, carregam e expressam fé neste orixá, lemanjá, conhecida popularmente como Rainha do mar. $^{7}$

Em 2008, a Lei estadual 12.988, do dia 13 de junho, declarou a Festa de Nossa Senhora dos Navegantes e de lemanjá, celebradas anualmente nos municípios do Rio Grande e São José do Norte, como integrantes do patrimônio cultural do Estado do Rio Grande do Sul. ${ }^{8}$ O reconhecimento político da festa em Rio Grande e em São José do Norte é um demonstrativo da vitalidade da mesma e da mobilização popular, considerando os registros de que, ao menos nos últimos cinquenta anos, milhares de pessoas comparecem às praias com diferentes objetivos que englobam desde demonstração de fé até desenvolvimento de atividades comerciais. O decreto, no entanto, torna-se um mote importante para o desenvolvimento deste ensaio visual, que busca evidenciar as referidas festas de lemanjá a partir da consideração deste evento enquanto bem cultural e na perspectiva do patrimônio cultural desta expressão de religiosidade afro-brasileira, em duas cidades do sul do Estado: Rio Grande e Pelotas.

humana, produzindo significações, hipóteses, proposições, explicações sobre determinadas práticas culturais (OLIVEIRA, 2006).

\footnotetext{
${ }^{5}$ Nosso exercício de análise das fotografias presentes neste ensaio considera não as imagens em si, mas a problematização que estamos propondo, de interpretá-las à luz das considerações da religiosidade festiva afro-brasileira enquanto bens culturais e patrimônios culturais. Portanto, considerando o contexto de produção das fotografias, devemos destacar que as imagens utilizadas neste texto são produções dos próprios autores, a partir de suas motivações de pesquisa vinculados ao "lugar" institucional acadêmico. Tais imagens são inéditas e não merecerem, até então, nenhuma circulação (LIMA; CARVALHO, 2013).

${ }^{6}$ Quando dizemos religiões de matriz africana, estamos nos referindo, especificamente e principalmente, a duas práticas religiosas experenciadas por alguns grupos no Rio Grande do Sul: o Batuque, religião de herança ancestral africana baseada no culto aos orixás, conhecido como Candomblé em outras partes do Brasil, mas com características próprias, como a reverência de apenas doze divindades; e a Umbanda, religião brasileira, baseada em manifestações espirituais para a promoção da caridade, formada a partir de elementos católicos, indígenas, espíritas e também africanos, na medida em que, como influência da cultura Nagô, "recebe o culto aos orixás, reverenciados na natureza, sendo oferecidos a eles frutas, flores, velas e bebidas" (CUMINO, 2010, p.55). Sobre Batuque, ver CORRÊA, 2006.

7 lemanjá é um orixá feminino do panteão das religiões afro-brasileiras considerada "mãe" de todos os
orixás e de todos os humanos. No Batuque, segundo a ordem de culto da "nação cabinda", é o $11^{\circ}$ orixá a
ser cultuado. Considerando que os orixás são identificados com as "forças" e os elementos da natureza,
lemanjá seria cultuada no mar, seria o próprio mar-oceano. Daí sua identificação como protetora dos
pescadores, marinheiros, portuários e de todos trabalhadores vinculados ao mar.
}

8 Disponível em:<http://www.al.rs.gov.br/filerepository/repLegis/arquivos/12.988.pdf>. Acesso em 23 fev. 2015 , às 15:38. 
Evidentemente, as festas dos Navegantes e de lemanjá não são celebradas apenas nestas duas cidades, mas em várias outras cidades do Rio Grande do Sul (e mesmo do Brasil) sejam elas com praias banhadas pelo Oceano ou pela Laguna dos Patos.

Assim, a exclusão da análise da festa realizada em São José do Norte e da referência à festa de Nossa Senhora dos Navegantes, se justifica por dois fatores principais: o fato de este ensaio ser uma reflexão preliminar, e bastante sucinta, de um projeto de pesquisa em fase inicial, bem como o nosso interesse em referenciar exclusivamente o culto, a devoção e a referência cultural festiva dedicada à lemanjá, principalmente por integrantes dos cultos afro-brasileiros, ainda que, inevitavelmente, façamos referência à Nossa Senhora dos Navegantes.

O reconhecimento desta festa enquanto patrimônio intangível - especialmente em Rio Grande e São José do Norte - torna-se relevante para, através das ações de salvaguarda desse bem cultural vivo e dinâmico, garantir a permanência do evento e da manifestação e viabilizar meios de investimentos públicos e privados. Desse modo, temse garantido o auxílio financeiro aos religiosos de matriz africana que se ocupam de organizar o evento, fornecendo palco, som, iluminação, além de o mínimo de estrutura necessária como serviço de segurança, de primeiros socorros, de limpeza, de fornecimento de banheiros públicos, etc. ${ }^{9}$

Primeiro, apresentamos fotografias da festa de lemanjá da praia do Cassino, em Rio Grande, capturadas na noite do dia 01 para o dia 02 de fevereiro de 2015, festa realizada desde 1975, portanto, em sua 40a edição. Depois, apresentaremos fotografias da festa de lemanjá realizada na tarde do dia 02 de fevereiro, na praia do Laranjal (Balneário dos Prazeres, também conhecido como "Barro Duro"), na cidade de Pelotas.

A Figura 01 apresenta a santa (o orixá é também chamado de santa pelos religiosos de matriz africana) cultuada na praia do Cassino em Rio Grande, completamente branca, ${ }^{10}$ adornada com coroa, manto azul claro bordado, colares e "guias" de contas brancas e azuis e grande variedade de flores brancas e de outras brancas coloridas com azul. Esta escultura de lemanjá recebeu iluminação especial, como fica bem evidenciado na Figura 02, onde também é possível perceber a variedade de placas como espécies de "ex-votos", colocadas por fiéis, além de grande quantidade de "oferendas", entre flores, adornos, bebidas e comidas.

\footnotetext{
${ }_{9}$ Neste mesmo sentido, veja-se COUTO, 2012, p. 129.

10 Nesse caso, o aspecto branco da santa refere-se ao estilo da escultura como um todo. No entanto, se por um lado, nos parece pertinente o questionamento quanto ao fenótipo branco da cor da pele das imagens de lemanjá, de um modo geral, por outro, é desta forma que os religiosos de matriz africana a representam nas praias brasileiras.
} 
Nota-se uma grande quantidade de garrafas de espumantes e frutas, além de flores e oferendas diversas em bandejas decoradas com 'papel plástico'. Todas estas oferendas estão, de alguma forma, relacionadas ao simbolismo de lemanjá na Umbanda e no Batuque e em consonância com a mitologia africana. Portanto, fazem parte deste emaranhado de elementos: barquinhos azuis, melancias (a fruta típica dedicada à santa), velas azuis em grande quantidade, flores, perfumes, leques, espelhos. E também a oferenda típica realizada pelos batuqueiros, na praia ou no "quarto de santo" (espaço sagrado no interior da casa de religião, onde "ficam" os santos, as velas e as oferendas), geralmente formada por canjica branca, merengues e mel, entre outros elementos, um pouco variados, conforme a "nação" a qual pertence o religioso. ${ }^{11}$

Além do grande amontoado de "presentes" à lemanjá, nota-se ao fundo o fogo (Fig. 04), efeito das velas que foram acendidas ao redor, geralmente em número de oito ou seus múltiplos (cada orixá está associado a um número e o de lemanjá é oito). Observa-se que o fogo das velas ganha, às vezes, grandes proporções, alimentado pelo vento e pelas bebidas alcoólicas também ofertadas.

São muitas as cenas que, em observação participante, o pesquisador pode presenciar na tentativa de compreender a importância social e religiosa atribuídas à festa. Nesta direção, é possível ver pessoas ajoelhadas ou agachadas fazendo seus pedidos, suas orações, seus agradecimentos, e ouvir os religiosos cantarem seus "pontos", como este: "Eu vou levar flores no mar prá lemanjá / Uma promessa eu fiz para a Deusa do mar / Eu pedi, recebi, prometi, vou levar". Outros "rezam" silenciosamente, "conversam" com a santa e muitas velas são acesas (Fig. 04 e 05).

A ideia da abundância tal como a do axé (energia e força vital) de fartura nos rituais religiosos de matriz africana também está presente e evidenciada na grande quantidade de bebidas, flores, alimentos e velas que uma única pessoa é capaz de levar, indicando a relação diretamente proporcional entre as fartas oferendas e a crença de maior proteção, eficácia e brevidade da "resposta" do axé (Fig.02 a 05).

Nossa observação permite registrar que na festa, pais (babás) e mães (yás) de santo - em geral, representantes do Batuque - devidamente trajados com suas vestes religiosas (axós), reverenciam lemanjá. A grande quantidade de pessoas trajando roupas brancas ou não, se aglomeram ao redor da escultura realizando suas súplicas e agradecimentos. Diversas são as formas que, diante da imagem santa, os fiéis/devotos a

\footnotetext{
11 Fazemos aqui duas observações. Batuqueiro é como os próprios religiosos, seguidores do Batuque, se autorrepresentam. "Nação", muitas vezes tomadas como sinônimo de Batuque ("Sou de Nação" / "Sou do Batuque"), diz respeito às variáveis do culto aos orixás no Rio Grande do Sul. Cada "nação", que inicialmente designa uma procedência africana específica, indica, na prática, um modo sutilmente diferente de cultuar os orixás e manter seus "fundamentos" religiosos (todos baseados na oralidade). O Batuque se subdivide, então, nas seguintes nações: ljexá, Jeje, Nagô, Cabinda, Oyó. Sobre o assunto, ver mais em: CORRÊA, 2006.
} 
ela se remetem: ajoelhados simplesmente, ajoelhando com elevação e exposição das mãos, agachadas, de pé em postura de admiração e adoração ou, ainda, batendo cabeça no chão, como se no terreiro (casa de religião) estivesse (Figura 05). São estas, evidências destes instantes de experiências sagradas e de demonstração pública dos sentimentos e emoções religiosas.

Poder-se-ia também registrar as práticas, em Rio Grande, observadas nos barracões, no palco e na areia, à beira mar, mas os limites deste ensaio não permitem. Vamos, portanto, nos atermos aos aspectos representados, a partir de nossa subjetividade, de nosso recorte e do nosso olhar, nas fotografias.

Ao longo da Avenida Rio Grande, significativa quantidade de pessoas se aglomeravam à espera da procissão que ocorreu após as 23h.Enquanto alguns esperavam, outros caminhavam pelas ruas e inúmeros comerciantes, de alimentos e bebidas, mas fundamentalmente de flores, velas e imagens religiosas faziam seus negócios (Fig. 06). A essa importância social, cultural e econômica atribuída à festa, há de se considerar também o crescimento do turismo como elemento de valorização cultural dessa comemoração, que tal como a festa do Senhor do Bonfim, na Bahia, acaba sofrendo um "processo de espetacularização" passando a ser vista como exótica, capaz de se transformarem "atrativos turísticos a serem comercializados" (SANTANA, 2009, p. 33).

Em Pelotas, a ritualística festiva de lemanjá, em sua $58^{a}$ edição, é significativamente diferente da festa ocorrida em Rio Grande. A imagem de lemanjá, presente em uma gruta na praia do Laranjal (Balneário dos Prazeres), aguardava, na tarde do dia 02 de fevereiro, o encontro com a imagem católica de Nossa Senhora dos Navegantes nas águas da Lagoa dos Patos (Fig. 07).

Para os religiosos, o instante em que a embarcação com a imagem da Senhora dos Navegantes e o andor com a imagem de lemanjá se encontraram na água da lagoa foi um dos momentos mais importantes, significativos e esperados da festa (Fig. 07). Esse instante revela o quanto ainda são intensas e "eficazes", no Brasil, as relações interativas entre as religiões, o quanto são evidentes as zonas de contato, tênues as demarcações das fronteiras e fluídos os significados atribuídos ao culto aos santos católicos e africanos. $^{12}$

A procissão fluvial de lemanjá foi acompanhada por inúmeros fiéis, devotos e turistas que, ou permanecem na encosta ou adentram as águas acompanhando a imagem. Aqueles que participavam acompanhando de perto a imagem de lemanjá

12 Para reflexões nesse sentido, ver DILLMANN e RIPE, 2012. Um bom estudo das relações entre o culto à Nossa Senhora dos Navegantes e lemanjá, em Porto Alegre/RS, ver ORO e ANJOS, 2009. 
lançavam água para cima em direção à santa, configurando um verdadeiro jogo comemorativo das águas (Fig. 09). No andor, a imagem seguia adornada de modo semelhante à imagem da praia do Cassino: flores, colares com contas de pérolas, manto azul claro e coroa. Contudo, um aspecto tornava-a diferenciada: a imagem era adornada por longos cabelos pretos naturais, o que remete não apenas à intenção de promover um embelezamento, mas também de aproximar, simbolicamente, o divino ao humano ${ }^{13}$ (Fig. 09). A humanização promovida à imagem através do recurso capilar - popularmente conhecido como doação de uma devota como pagamento de promessa por uma graça alcançada - pode trazer maior identificação entre o devoto e o orixá, pois essa relação entre aquele que devota e o santo que é devotado, além de se expressar pelos sentimentos, materializa-se em objetos.

Ao fim da procissão fluvial, a chegada da imagem à gruta, numa área coberta (Fig. 10), foi acompanhada pelos fiéis com grande expectativa que a receberam com muitas palmas. Na sequência, a banda da Brigada Militar entoou o hino da Umbanda (Fig. 11), emocionando muitos dos devotos que estavam presentes.

Com base nestas considerações, observamos que tanto em Rio Grande quanto em Pelotas as festas de lemanjá configuram-se enquanto expressões culturais religiosas de matriz afro-brasileiras, representadas em espaços culturais devidamente associados a tais práticas ritualísticas e comemorativas, as praias do Cassino e do Laranjal. ${ }^{14}$ No domínio dos acontecimentos festivos, enquanto bem cultural representativo da identidade religiosa de determinado grupo social, a festa de lemanjá da cidade do Rio Grande conta com o status de patrimônio cultural do Estado desde 2008; já, a festa de lemanjá de Pelotas, embora mais antiga que a rio-grandina e bastante peculiar por ser a única no Estado - e quiçá no Brasil - a promover o encontro das santas (católica e afro) na procissão fluvial, parece estar longe do processo de patrimonialização, por enfrentar, atualmente, indeterminação política quanto ao local de permanência da gruta ou mesmo a sua manutenção na praia. Em ambas as festas, como demonstramos a partir das imagens, os vínculos religiosos e devocionais à comemoração do orixá lemanjá são/estão - segundo nossa observação participante baseadas no ver/ouvir/escrever fortalecidas e, enquanto prática cultural, estão em constante possibilidade de recriação

\footnotetext{
${ }^{13}$ Essas relações de proximidade que os fieis expressam em relação ao santo de devoção foram abordadas, entre outros, pela antropóloga Léa Freitas Perez (2011, p. 154), que considerou as peculiaridades das expressões de religiosidades brasileira, marcadas pela dimensão festiva, carnal, pública, teatral. Devoção fervorosa caracterizada pela adoração aos santos, realização de promessas e mandingas.

14 A compreensão social dos significados de tais práticas religiosas festivas e comemorativas conduz à valorização e mobilização da comunidade à preservação, uma vez que oportuniza identificação e pertencimento. Mecanismos eficazes no sentido de garantir esta compreensão é a Educação Patrimonial. Nesse sentido, ver SCHIAVON; SANTOS, 2011, p. 80.
} 
dos seus sentidos pelos próprios agentes festivos, mas ao mesmo tempo, tendem a enfrentar "as contínuas intimidações às tradições culturais (...) tão prosaicas na contemporaneidade" que "tem sinalizado a necessidade de os cidadãos exercerem seus direitos e se mobilizarem em favor da proteção das tradições populares e dos múltiplos e plurais bens culturais" (PELEGRINI; FUNARI, 2008, p. 09).

Figura 01 -Escultura de lemanjá adornada - Cassino/Rio Grande/RS

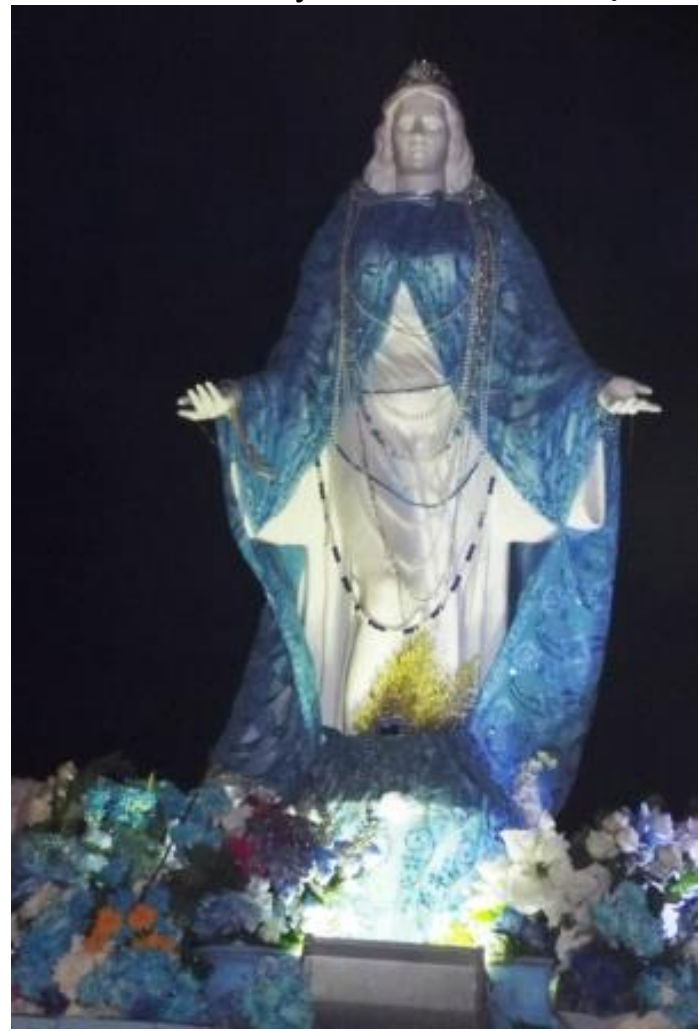

Fonte: Registro fotográfico realizado pelos autores, 2015. 
Figura 02 -Escultura de lemanjá e seu entorno - Cassino/Rio Grande/RS

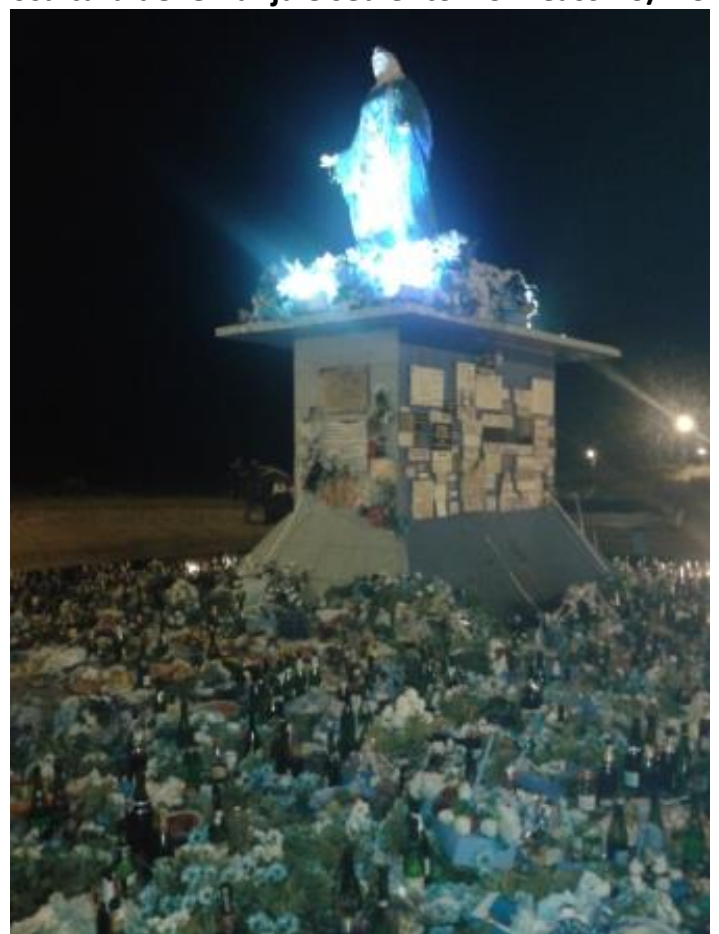

Fonte: Registro fotográfico realizado pelos autores, 2015.

Figura 03 -Detalhe das oferendas à lemanjá - Cassino/Rio Grande/RS

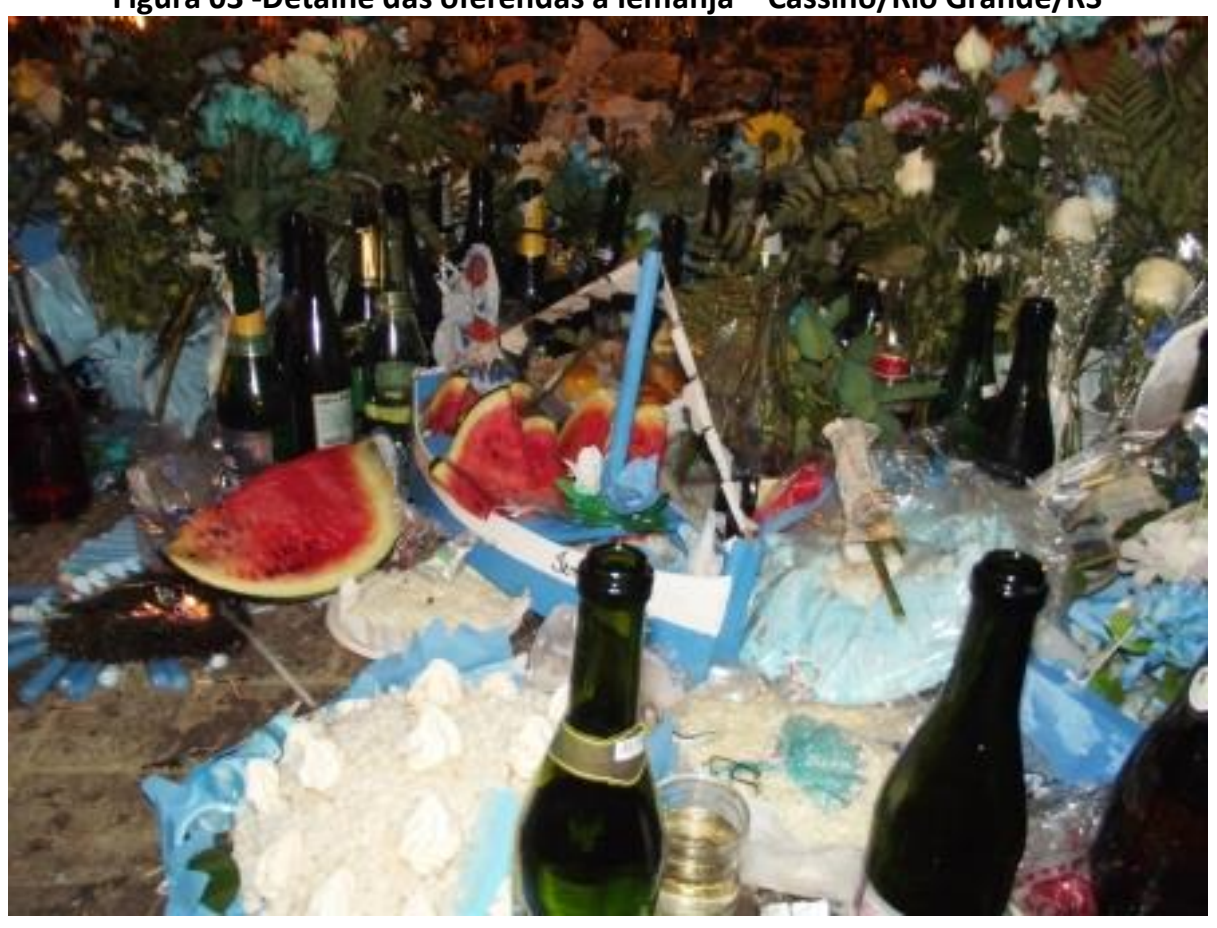

Fonte: Registro fotográfico realizado pelos autores, 2015. 
Figura 04 -Panorama das oferendas à lemanjá - Cassino/Rio Grande/RS

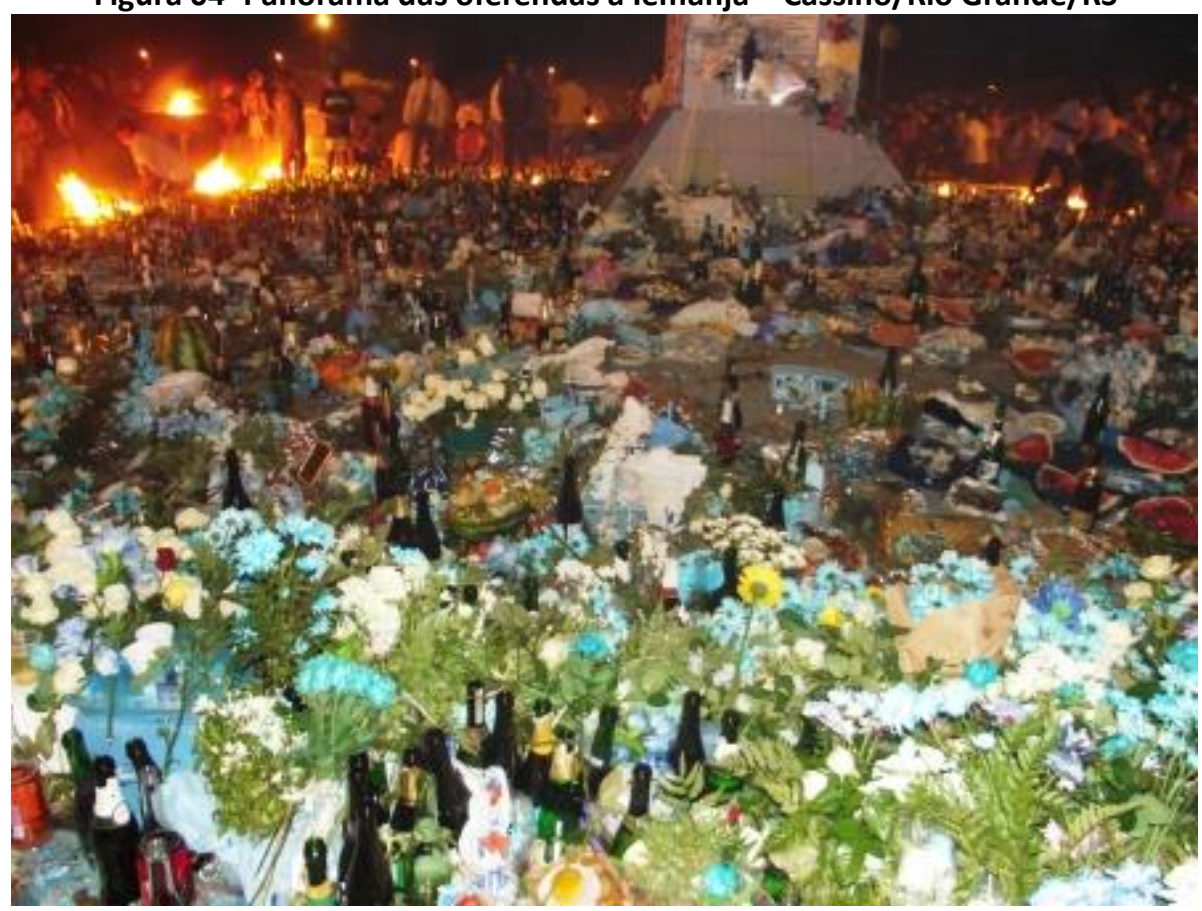

Fonte: Registro fotográfico realizado pelos autores, 2015.

Figura 05 -Expressão da devoção - Cassino/Rio Grande/RS

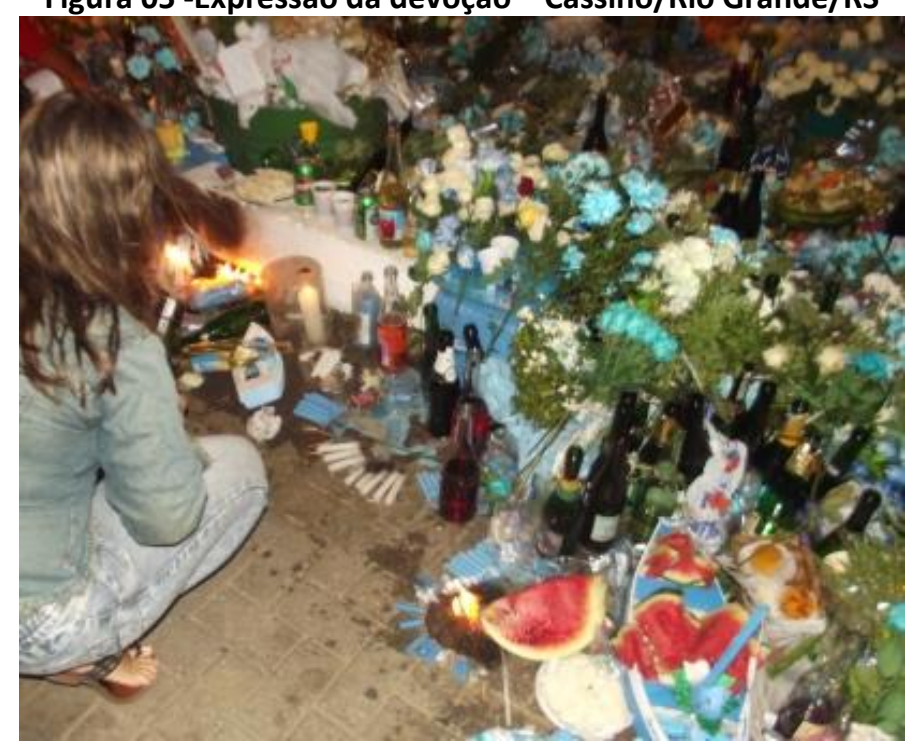

Fonte: Registro fotográfico realizado pelos autores, 2015. 
Figura 06 -Comercialização de objetos religiosos - Cassino/Rio Grande/RS
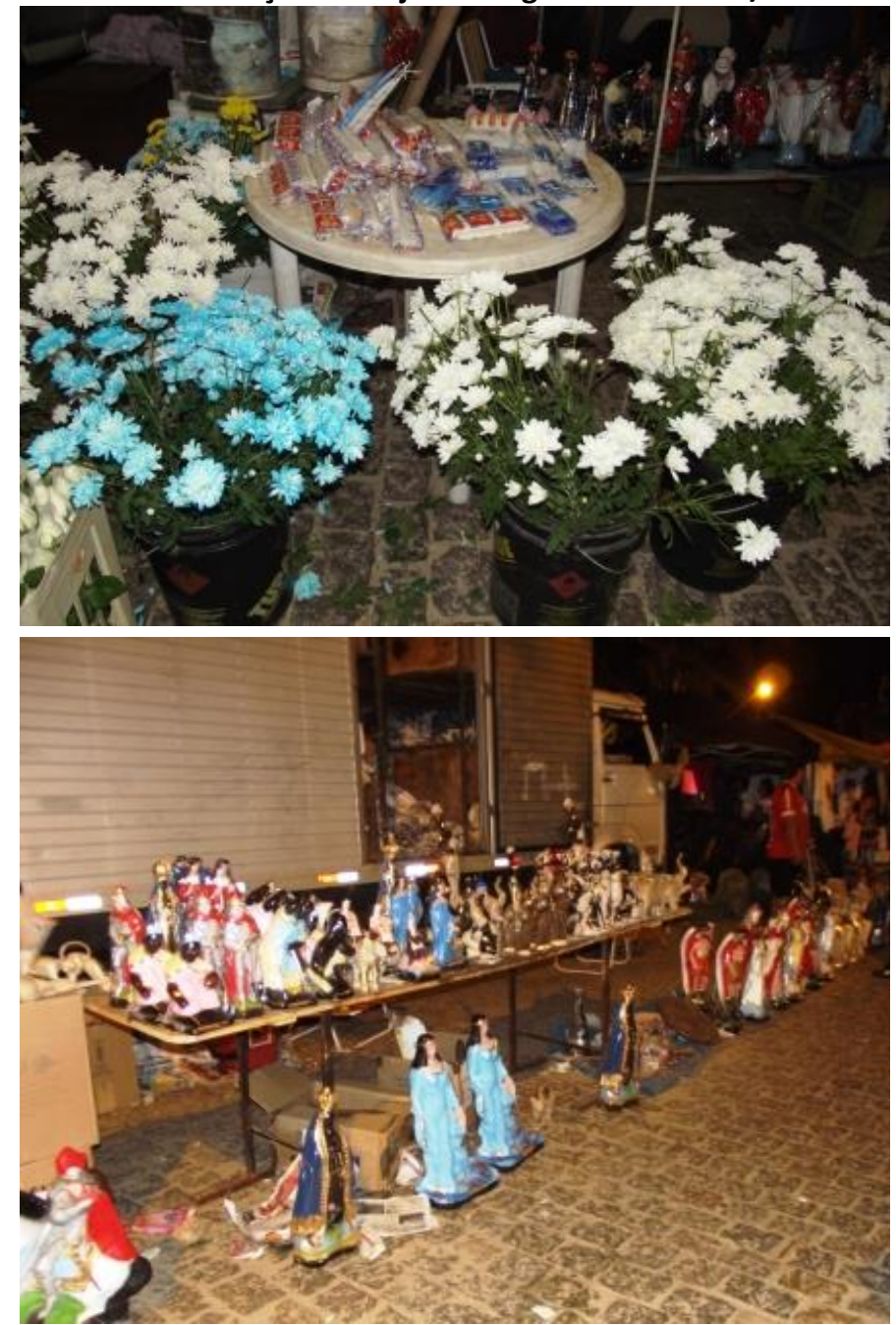

Fonte: Registro fotográfico realizado pelos autores,2015. 
Figura 07 -Procissão fluvial e encontro das imagens de Nossa Senhora dos Navegantes e lemanjá Laranjal/Pelotas/RS
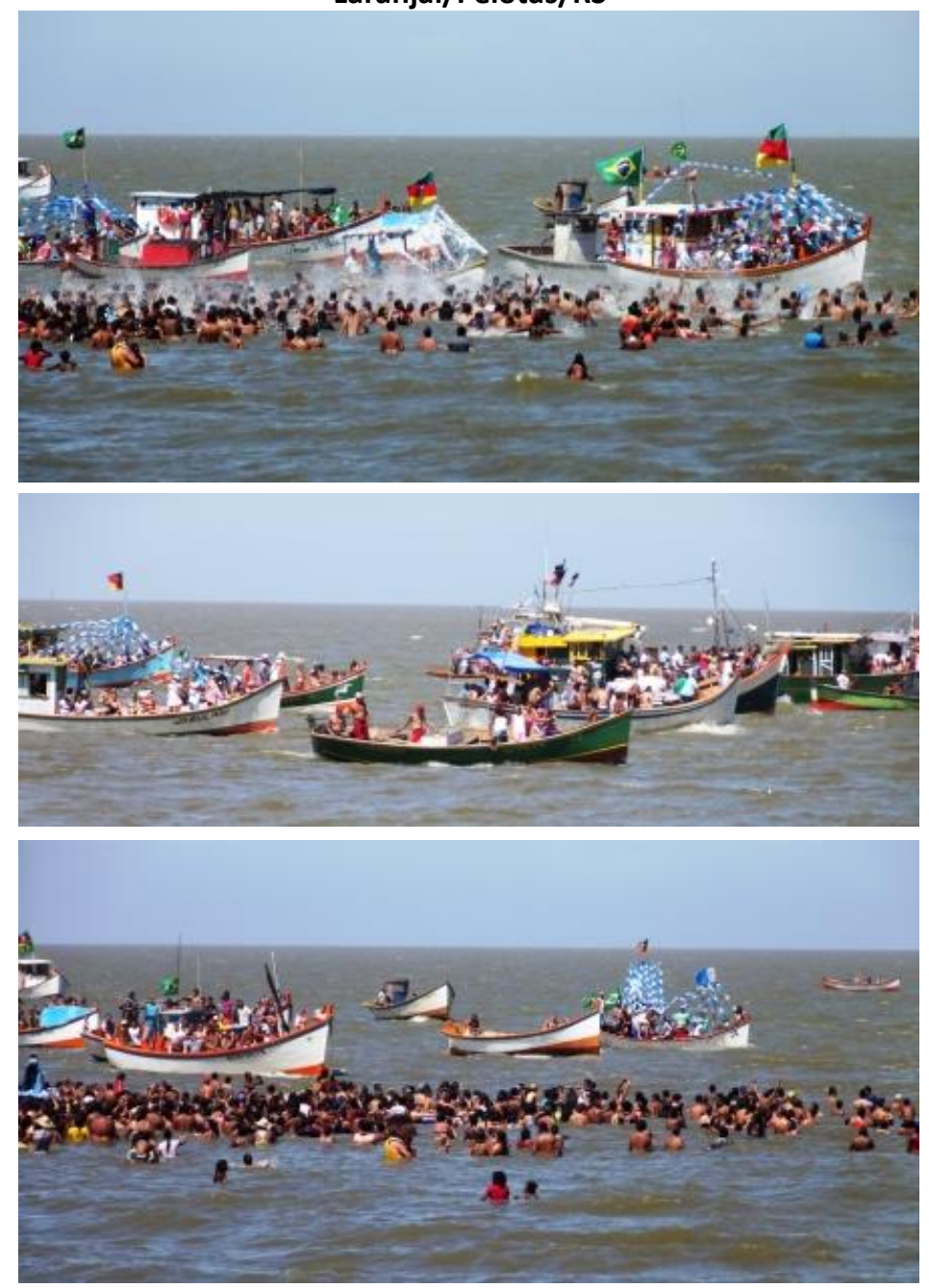

Fonte: Registro fotográfico realizado pelos autores, 2015.

Figura 08 -Detalhe da procissão fluvial de lemanjá - Laranjal/Pelotas/RS

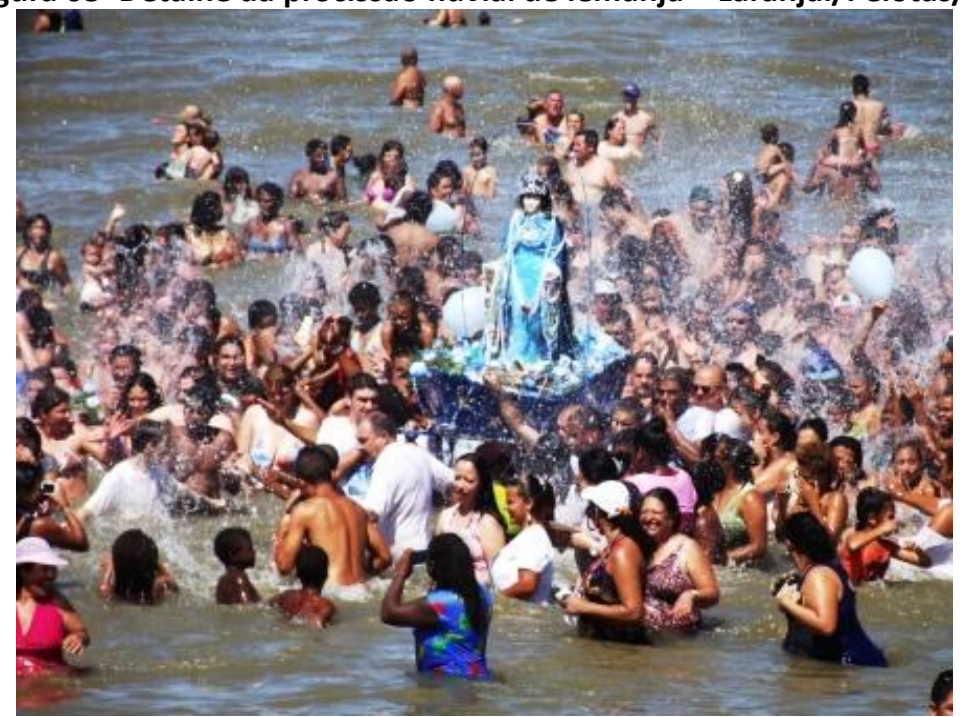

Fonte: Registro fotográfico realizado pelos autores, 2015. 
Figura 09 -Prática do jogo comemorativo das águas - Laranjal/Pelotas/RS



Fonte: Registro fotográfico realizado pelos autores, 2015.

Figura 10 -Chegada da imagem de lemanjá à Gruta - Laranjal/Pelotas/RS

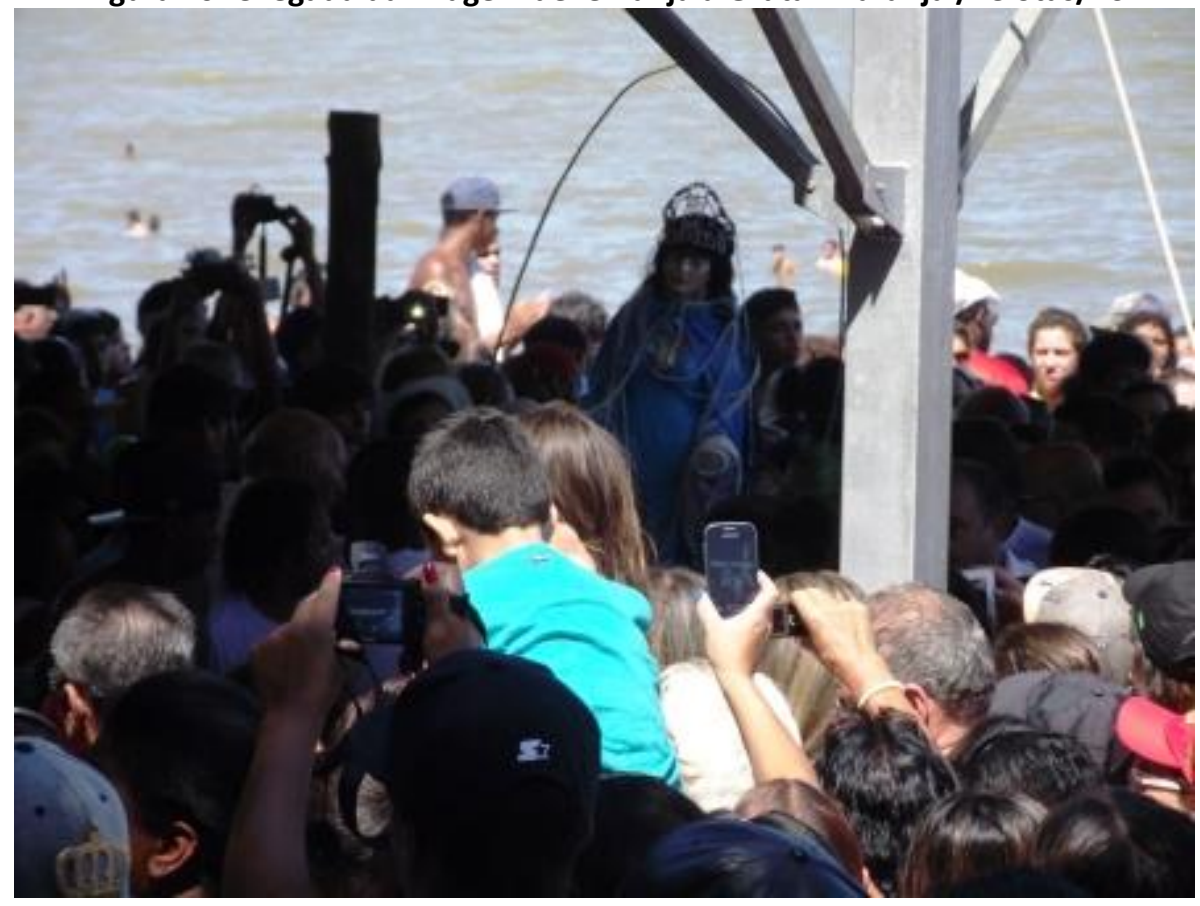

Fonte: Registro fotográfico realizado pelos autores, 2015. 




Fonte: Registro fotográfico realizado pelos autores, 2015.

\section{REFERÊNCIAS:}

CORRÊA, Norton F. O Batuque no Rio Grande do Sul: antropologia de uma religião afroriograndense. 2.ed. São Luís: Cultura \& Arte, 2006.

COUTO, Edilece Souza. Bárbara e lansã, as donas dos mercados de Salvador. In: RUBIM, Linda; MIRANDA, Nadja(Org.). Estudos da festa. Salvador: Edufba, 2012.

CUMINO, Alexandre. História da Umbanda: uma religião brasileira. São Paulo: Madras, 2010.

DILLMANN, Mauro; RIPE, Fernando. Resenha de FICHTNER, Mirian. Cavalo de santo: religiões afro-gaúchas. Porto Alegre, 2010. In:Horizontes Antropológicos, Porto Alegre, ano 18, n. 37, p. 411-414, jan./jun. 2012.

LIMA, Solange Ferraz de; CARVALHO, Vânia Carneiro de. Fotografias: usos sociais e historiográficos. In: PINSKY, Carla Bassanezi; DE LUCA, Tania Regina. O historiador e suas fontes. São Paulo: Contexto, 2013, p. 29-60.

OLIVEIRA, Roberto Oliveira de. O trabalho do antropólogo. 3. ed. São Paulo: Paralelo 15, 2006. ORO, Ari Pedro; ANJOS, José Carlos Gome dos. Festa de Nossa Senhora dos Navegantes em Porto Alegre: sincretismo entre Maria e lemanjá. Porto Alegre: SMC, Instituto Estadual do Livro, 2009. 
PELEGRINI, Sandra P. A.; FUANRI, Pedro Paulo. O que é patrimônio cultural imaterial. São Paulo: Brasiliense, 2008.

PEREZ, Léa Freitas. Festa, religião e cidade:corpo e alma do Brasil. Porto Alegre: Medianiz, 2011.

SANTANA, Mariely Cabral de. Alma e festa de uma cidade:devoção e construção na Colina do Bonfim. Salvador: Edufba, 2009.

SCHIAVON, Carmem G. Burgert; SANTOS, Tiago Fonseca dos. Ilha dos Marinheiros: o patrimônio e a história como alicerces à educação patrimonial. In: SCHIAVON, Carmem G. Burgert; SENNA, Adriana Kivanski; SILVA, Rita de Cássia Portela. Sul do Sul: memória, patrimônio e identidade presença luso-açoriana em Rio Grande. Porto Alegre: EST Edições, 2011, p. 78-87. 